\title{
'It's all about coping with the new specifications': Coping professional development - the new CPD
}

\author{
Laura Molway* - University of Oxford, UK
}

\begin{abstract}
This article addresses the issue of in-service teacher education, which has become a focus of international education policy attention in recent years. Professional learning $(\mathrm{PL})$ is often envisioned by policymakers as a mechanism by which the professionalism of the teaching workforce can be remodelled and refreshed. It offers a means to enhance teachers' professional efficacy and, consequently, the outcomes of students. The article examines the case of England, and takes a single subject area (modern foreign languages) as the context in which to explore teachers' PL experiences over the course of one calendar year. Data tracking the PL priorities and experiences of 54 teachers clustered in 14 state school languages departments were collected via four iterations of an online questionnaire. This was followed by in-depth semi-structured interviews with heads of department in six of the schools, enabling a process of triangulation. Analysis shows very limited engagement in PL activities of the kind identified in previous literature as effective in impacting student outcomes. In all the schools, teachers' PL experiences were shaped by a sharp focus on instrumental organizational aims related to the introduction of new examination specifications and curricula, reducing available time and resources for the pursuit of other development goals. A large amount of the variance in teachers' reported engagement in PL activities known to be effective can be explained by school membership. Heads of department recognize their role in shielding colleagues from excessive workload and promoting collaborative PL. However, they report varying degrees of agency in addressing contextual barriers to achieving these aims. In contexts where teachers report high levels of stress, this is associated with lower professional self-efficacy, engagement and intention to remain in the profession.
\end{abstract}

Keywords: continuing professional development; professional learning; teacher education; curriculum change; modern foreign languages

\section{Introduction}

Individual teacher effectiveness is one of the most significant factors in predictions of student attainment (Schleicher, 2016; Sutton Trust, 2011). One way to positively impact student outcomes is therefore to ensure that teachers continue to develop and improve their classroom practice (Day et al., 2006). The importance of induction programmes to support the practice of new entrants to the profession has been widely acknowledged and implemented in education policy around the world (Schleicher, 2011). However, in recent years, attention has shifted to the development needs of in-service teachers at all career stages, and this has been the focus of recent comparative studies of PL in world-leading education systems (Darling-Hammond, 2017; Jensen et al., 2016). Using data from the Programme for International Student Assessment (PISA) and the 
Teaching and Learning International Survey (TALIS) as a starting point, these studies have identified that high-performing countries and provinces adopt system-wide strategies to create conditions for teacher learning that tend to be school-embedded, linked to student learning, well-resourced (in terms of allocated time within teachers' working week), collaborative and sustained over time (rather than taking the form of short, one-off courses).

In England, where the current study is situated, evidence about the importance of teacher quality has been used to justify a policy focusing on raising the bar for entry to the profession (for example, a range of initial teacher training bursaries have been introduced, the value of which increases in line with applicants' degree classification (see https://getintoteaching.education.gov.uk). These policies have been criticized for their short-term nature $(N A O, 2017)$ and for failing to address issues of teacher support and workload that have been identified as key in safeguarding against teachers exiting the profession (Coldwell, 2017; Foster, 2018). Day and Gu (2007) argue that UK policy should focus on high-quality support and PL for teachers at all career stages to maintain their sense of efficacy and commitment to the profession. Teachers in England report relatively low amounts of time spent participating in PL activities. (England ranked 30th out of 36 jurisdictions included in the 2013 TALIS data set for time spent on the categories of $\mathrm{PL}$ included.) They also report relatively low impact of those activities on their classroom practice (Sellen, 2016). Cordingley et al. (2015) suggest that teachers in England face high workloads, and so struggle to find the time for PL. Time and funding pressures may also have led to the prevalence of a whole-school delivery model for $\mathrm{PL}$ within schools in England, with school leaders employing economies of scale and prioritizing whole-school improvement agendas. Three key concerns associated with PL in England have been identified: (1) the poor quality of much PL provision reduces its impact (that is, participants are less likely to transform their practice as a result); (2) participation in PL is insufficiently incentivized; and (3) many schools offer poor environments for teacher learning (Hood, 2016).

In a first step towards addressing these issues, the Department for Education (DfE, 2016) in England recently published an ambitious standard for teachers' professional development, which draws explicitly and extensively on the recommendations of research into teachers' PL by Cordingley et al. (2015). Although the guidance in this document is not statutory, it nonetheless represents an effort to raise awareness about what constitutes effective PL, and to improve teachers' access to sustained and effective $\mathrm{PL}$ programmes. Therefore, there is now a requirement for research that focuses on the PL needs and experiences of a range of in-service teachers at different career stages in England to evaluate the implementation and impact of these well-meaning policy changes on the front line.

\section{The characteristics of effective professional learning for teachers}

'Effective' PL is defined for the purposes of this article as any learning experience that leads to improvements in valued student outcomes (see Timperley, 2008). It is, however, difficult to collect rigorous evidence of the impact of teachers' PL on student outcomes due to issues surrounding the measurement of both teacher and student learning and the web of confounding factors that may affect such measurement attempts in the field (Darling-Hammond et al., 2012). A PL experience may result in varying degrees of teacher change: 'teachers may change their beliefs but not their practices, may change their practices but not their beliefs, and ultimately may change 
their practice but not the learning outcomes of their students' (Opfer and Pedder, 2011: 386). Despite these difficulties, there is a growing body of associational research that links some specific features of PL with improvements in student learning. The most comprehensive and rigorous recent meta-analysis reports on the findings from nine systematic research reviews about effective PL activities (Cordingley et al., 2015). A large degree of convergence across the review findings was noted, and the authors emphasize the importance of access to external expertise; sustained engagement with new ideas; and formative assessment of teachers' PL with a focus on student outcomes. Cordingley (2015: 240-1) summarizes these review findings in the form of eight teacher actions that commonly characterize effective PL:

1. Making use of specialist expertise, including expertise in the form of research evidence; using evidence and expertise to support planning in particular.

2. Giving and receiving structured peer support using collaboration, especially reciprocal risk taking and professional dialogue, as core learning strategies.

3. Undertaking sustained, enquiry-orientated learning over (usually) two terms or more, supported by use of tools and protocols to discipline learning and secure coherence and progression.

4. Learning from looking through exploration of evidence about pupil outcomes, and from observing teaching and learning exchanges, especially those involving experiments with new approaches.

5. Using aspirations for specific pupils and evidence about their learning as a driver for development.

6. Focusing on why things do and do not work in different contexts to develop an underpinning rationale or practical theory alongside practice.

7. Seeking out leadership support - time/encouragement/modelling - including specialist coaching and engaging in enquiry-orientated approaches to development.

8. Actively seeking out specialist and peer support and taking responsibility for creating and taking opportunities for professional learning within day-to-day school life.

The content and focus of PL activities most likely to lead to improvements in student learning have also been widely discussed in recent years. PL has been found to be most effective when it is directly focused on enriching teachers' subject-specific content and pedagogic content knowledge (the term coined by Shulman in 1986), or when it contextualizes generic pedagogic strategies for individual subject areas (Cordingley et al., 2018).

In addition to the content and design of PL activities, there is a complex interplay between individual socio-cognitive and contextual factors that are known to affect the efficacy of teachers' PL (Hodkinson and Hodkinson, 2004). Individual teachers may themselves exhibit a range of personality traits, motivations and learning dispositions. Each teacher influences, and is influenced by, their department team, nested in a wider whole-school context, which is in turn subject to influence from local, national and global discourses, policies and agendas (Childs et al., 2013). This article focuses on contextual factors at school and department level. The responses of individual schools to the wider context can foster or inhibit conditions for teacher learning: for example, a major impediment to engagement in PL is known to be excessive workload (Sellen, 2016), and some school environments are more successful than others in tackling this. Contexts where a focus on performance in accountability measures leads to 'increased email contact with parents, data entry demands by school leaders and fashionable 
theories of "deep marking"' may erode teachers' capacity to engage in PL (Adams and Stewart, 2018: 1). Stress-induced exhaustion, cynicism and inefficacy clearly detract from engagement in $\mathrm{PL}$, and Friedman $(1991,2000)$ has identified four characteristics of a school culture that can lead to this type of burnout: (1) an emphasis on measurement of performance and accountability by school leadership; (2) a lack of trust in the skills of teachers; (3) a school culture perceived as controlling; and (4) an inadequate physical environment. Conversely, school environments that encourage feelings of teacher competence, autonomy and collegial support have been identified as fostering teacher motivation towards innovative teaching (Lam et al., 2010). Collaborative learning environments are important in satisfying teachers' needs for relatedness and avoiding isolation (Burn et al., 2010), but such environments must not become closed loops, vulnerable to the unchallenged propagation of pre-existing ideas and threatened by non-conformity (Fullan and Hargreaves, 1992; Opfer and Pedder, 2011). The collaborative learning cultures of different departments have been explored by Childs et al. (2013), who highlighted the key influence of the head of department and the importance of a shared space such as a team room.

\section{The current context for teachers of second languages in England}

In England, as in some other Western education systems (see, for example, Zeichner, 2010; Leonard and Roberts, 2016), the trend in recent years has been towards increased accountability and surveillance within the teaching profession in an attempt to 'measure and demonstrate professionalism' (Evetts, 2011: 412) and to improve standards of teaching and learning in all schools (see Hargreaves et al., 2006; Schleicher, 2011). Accountability measures, performance-related pay and policies such as national strategies and standards can be understood as both professionalizing, through setting benchmark standards and skills, and also 'deprofessionalising, or taking away pedagogical autonomy' (Hargreaves et al., 2006: 6). However, movement towards externally imposed standards is most widely understood in the international literature as undermining teachers' professionalism: Sachs (2016: 416) argues that an overload of accountability measures in schools 'erodes trust and develops risk-adverse [sic] dispositions towards practice'. This tendency can be seen in the following quotation from a 2014 survey of languages teachers in England:

Generally it is recognised that teachers are not teaching languages the way they would like to and do not feel that they have the scope to innovate. A culture has developed where few are willing to risk missing the highest grades in return for learning something interesting but not relevant to the exam. (Ipsos MORI, 2014: 42)

The current study focuses on teachers of second languages (L2) in England. Student outcomes for L2 education in England do not compare well internationally (European Commission, 2012). Many researchers have argued that $L 2$ teaching in England has been shaped by years of high-stakes assessment that has encouraged the prioritization of rote learning and memorization above the development of communication skills (East, 2015; Macaro et al., 2016). L2 teachers in England may therefore need support to develop more effective L2 pedagogies.

In recent years, there have been many changes to the way in which languages are assessed in secondary schools in England: in 2014, a new national curriculum was introduced, and a centrally imposed system of assessing student attainment in the 
first three years of secondary school was withdrawn, leaving schools with the freedom to devise their own assessment systems. The changes to the national curriculum were swiftly followed by significant structural changes to the GCSE and A level languages examinations. For both GCSE and A level, the newly reformed qualification was introduced in 2016 and awarded for the first time in 2018. It is conceivable that sweeping changes in assessment structures could act as a catalyst for a system-wide re-evaluation of $L 2$ pedagogy and curriculum content with the potential to transform L2 teaching in England. However, there is evidence that L2 teachers have been left struggling to keep up with the pace of change, and that opportunities for a radical rethink of L2 pedagogy have been hindered due to financial pressures on England's state schools, which are reducing language teachers' access to subject-specific PL (Tinsley and Board, 2017).

\section{Research design}

This article explores two research questions:

1. To what extent are the PL experiences of teachers in the sample characteristic of 'effective' PL practices as reported in Cordingley (2015) and endorsed by the DfE (2016)?

2. What factors have shaped the PL experiences of teachers in the sample?

Data tracking the PL experiences of 54 teachers clustered in 14 state school languages departments were collected over a 12-month period via four questionnaires. These questionnaires were administered online in July 2016, November 2016, March 2017 and June 2017. Questionnaire data were followed up with in-depth semi-structured interviews with heads of department (HoDs) in six of the schools, enabling a process of triangulation.

All schools linked to one higher education institution via an Initial Teacher Education (ITE) partnership in the south-east of England were invited to participate in the study. Of the 47 schools approached, 14 agreed to participate. Although the schools are geographically close to each other, they vary greatly in size, diversity of student body and performance in standardized assessments, thereby encapsulating some of the wider diversity to be found across England and Wales. Each L2 teacher in these schools was invited to participate in order to obtain a cross-sectional sample of state school languages departments. Out of a possible 78 participants, between 45 and $54 \mathrm{~L} 2$ teachers participated in each iteration of the teacher questionnaire. Their experience of teaching ranged from 1 year to 15 or more years (see Table 1), and the combined average years of experience within each languages department ranged from 4.6 to 12.5 .

Table 1: Years of experience of L2 teaching at Time 1

\begin{tabular}{lcc}
\hline Experience & $\begin{array}{c}\text { Number of } \\
\text { respondents }\end{array}$ & $\begin{array}{c}\text { Percentage of } \\
\text { respondents* }\end{array}$ \\
\hline Early career & 12 & 22 \\
$\begin{array}{l}(1-5 \text { years' experience) } \\
\text { Mid-career }\end{array}$ & 13 & 24 \\
$(6-10$ years' experience) & 29 & 54 \\
$\begin{array}{l}\text { Experienced } \\
(11+\text { years' experience) }\end{array}$ & 29 & 54 \\
\hline
\end{tabular}

*Percentages are rounded to the nearest whole number 
Questionnaires were designed to measure a wide range of individual and schoollevel factors known to impact on teachers' $\mathrm{PL}$, drawing on a range of existing measures. For example, stress was measured by an adapted version of Fimian's Teacher Stress Inventory (1984) and teachers' sense of professional self-efficacy was measured via the Teachers' Sense of Efficacy Scale (TSES) (Tschannen-Moran and Woolfolk Hoy, 2001). Open-ended questions were followed by closed Likert-scale response formats, enabling the collection of both unprompted qualitative data and categorized, quantitative data for comparison with previously published research. Data regarding the focus, format, frequency and perceived impact of recent PL experiences were collected. Participants were also asked to consider whether they had undertaken any of the eight teacher actions thought to embody effective PL practices (Cordingley, 2015).

Research was conducted in line with BERA's ethical guidelines (2011). For tracking purposes, questionnaire links were personalized, and reminder emails were sent to encourage completion. Before analysis, unique IDs were assigned to each participant, preserving group affiliation and status while maintaining individual anonymity and reducing researcher bias. Teacher descriptions of their PL activities were coded according to categories used in the Organisation for Economic Co-operation and Development (OECD) surveys of teacher learning (Schleicher, 2016) and imported into a statistical software package (IBM SPSS). One-way ANOVAs were calculated to explore possible associations between aspects of teachers' reported PL, school membership, demographic variables, stress and self-efficacy levels.

Following analysis of the questionnaire data, HoDs were invited to participate in a follow-up interview at a time and place of their choosing. Out of a possible 14 HoDs, 6 agreed to participate (the HoDs at Douglas-Fir, Elm, Ginkgo, Ivy, Katsura and Nutmeg schools took part). The interviews were semi-structured and elicited rich explanations of HoDs' experiences and leadership of PL. Interviews were transcribed and anonymized before being imported into NVivo software for inductive coding and thematic analysis.

\section{Results and discussion}

\section{The nature of teachers' reported PL experiences}

The extent to which teachers felt they had engaged in the eight activities associated with effective PL (Cordingley, 2015) is detailed in Table 2. It is striking that over 40 per cent of overall responses indicated zero engagement. The least-reported activity was the undertaking of sustained, enquiry-orientated learning (activity 3): only 29 per cent of teachers felt that any elements of this had featured in their PL. The activities most frequently reported were those that emphasized peer support and the taking of opportunities for learning within day-to-day school life (activities 2 and 8). It is possible that these activities are the most accessible to teachers who may be time and resource poor. 
Table 2: The extent to which teachers perceived their recent PL activities to be characterized by the eight teacher activities linked to effective PL (Cordingley, 2015)

\begin{tabular}{|c|c|c|c|}
\hline \multirow[b]{2}{*}{ PL activity } & \multicolumn{3}{|c|}{$\begin{array}{l}\text { Frequency of response across all schools }(\%)^{*} \\
\qquad(n=42)\end{array}$} \\
\hline & $\begin{array}{l}\text { 'This was not a } \\
\text { feature of my } \\
\text { PL' }\end{array}$ & $\begin{array}{l}\text { 'Some } \\
\text { elements of } \\
\text { this featured in } \\
\text { my PL' }\end{array}$ & $\begin{array}{l}\text { 'This featured } \\
\text { strongly in } \\
\text { my PL' }\end{array}$ \\
\hline \multirow{2}{*}{$\begin{array}{l}\text { 1. Making use of specialist expertise, } \\
\text { including expertise in the form of research } \\
\text { evidence; using evidence and expertise to } \\
\text { support planning in particular }\end{array}$} & \multirow[t]{2}{*}{47.6} & 31 & 21.4 \\
\hline & & 52 & \\
\hline \multirow{2}{*}{$\begin{array}{l}\text { 2. Giving and receiving structured peer } \\
\text { support using collaboration, especially } \\
\text { reciprocal risk taking and professional } \\
\text { dialogue, as core learning strategies }\end{array}$} & \multirow[t]{2}{*}{28.6} & 50 & 21.4 \\
\hline & & 71 & \\
\hline \multirow{2}{*}{$\begin{array}{l}\text { 3. Undertaking sustained, enquiry- } \\
\text { orientated learning over (usually) two terms } \\
\text { or more supported by use of tools and } \\
\text { protocols to discipline learning and secure } \\
\text { coherence and progression }\end{array}$} & \multirow[t]{2}{*}{71.4} & 26.2 & 2.4 \\
\hline & & 28 & \\
\hline \multirow{2}{*}{$\begin{array}{l}\text { 4. Learning from looking through } \\
\text { exploration of evidence about pupil } \\
\text { outcomes and from observing teaching } \\
\text { and learning exchanges especially those } \\
\text { involving experiments with new approaches }\end{array}$} & \multirow[t]{2}{*}{45.2} & 42.9 & 11.9 \\
\hline & & 54 & \\
\hline \multirow{2}{*}{$\begin{array}{l}\text { 5. Using aspirations for specific pupils and } \\
\text { evidence about their learning as a driver for } \\
\text { development }\end{array}$} & \multirow{2}{*}{45.2} & 35.7 & 19 \\
\hline & & 54 & \\
\hline \multirow{2}{*}{$\begin{array}{l}\text { 6. Focusing on why things do and do not } \\
\text { work in different contexts to develop an } \\
\text { underpinning rationale or practical theory } \\
\text { alongside practice }\end{array}$} & \multirow[t]{2}{*}{31} & 42.9 & 26.2 \\
\hline & & 69 & \\
\hline \multirow{2}{*}{$\begin{array}{l}\text { 7. Seeking out leadership support - time/ } \\
\text { encouragement/modelling - including } \\
\text { specialist coaching and engaging in } \\
\text { enquiry-orientated approaches to } \\
\text { development }\end{array}$} & \multirow[t]{2}{*}{57.1} & 33.3 & 9.5 \\
\hline & & 42 & \\
\hline \multirow{3}{*}{$\begin{array}{l}\text { 8. Actively seeking out specialist and } \\
\text { peer support and taking responsibility } \\
\text { for creating and taking opportunities for } \\
\text { professional learning within day-to-day } \\
\text { school life }\end{array}$} & \multirow[t]{2}{*}{23.8} & 61.9 & 14.3 \\
\hline & & 76 & \\
\hline & \multirow{2}{*}{43.8} & 40.5 & 15.8 \\
\hline Mean scores across all eight activities & & 56 & \\
\hline
\end{tabular}

A look at the activities that teachers report as having been their most valuable learning opportunities during the 2016/17 academic year shows that a clear majority attribute the greatest value to subject-specific PL experiences: 63 per cent of all responses can be categorized as focusing on subject knowledge and understanding or subject-specific pedagogical competencies (see Table 3). There was also a significant correlation 
$(r=.43, p=0.008)$ between reported engagement in activities specifically designed for L2 teachers and the extent to which teachers felt that changes to their practice inspired by their PL had benefited their students. These results are as expected - previous research has demonstrated the high value that teachers attribute to PL focused on subject-specific teaching approaches - and confirms that PL contextualized within a subject area is associated with increased effectiveness (Cordingley et al., 2018).

Table 3: Frequency (\%) of teacher descriptions of their most valuable PL experiences

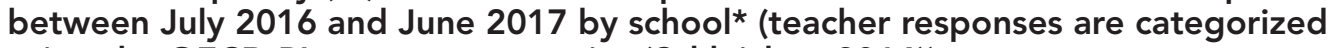
using the OECD PL content categories (Schleicher, 2016))

\begin{tabular}{|c|c|c|c|c|c|c|c|c|c|c|c|c|c|c|}
\hline & \multicolumn{14}{|c|}{ OECD categories of PL content } \\
\hline & 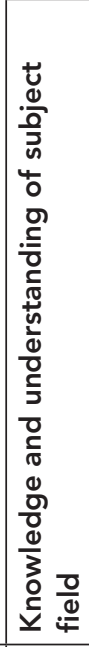 & 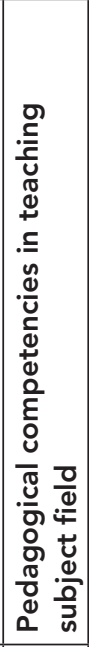 & 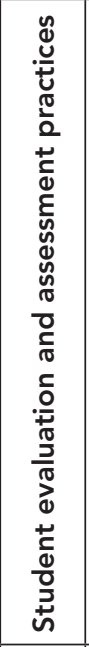 & 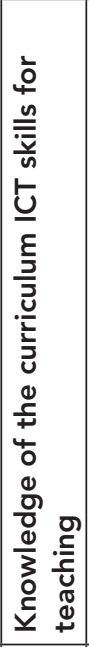 & 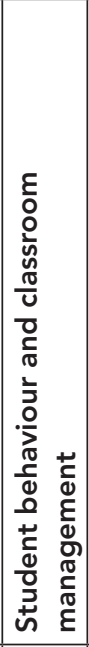 & 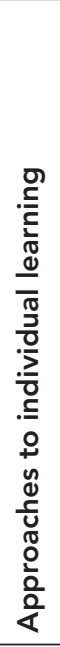 & 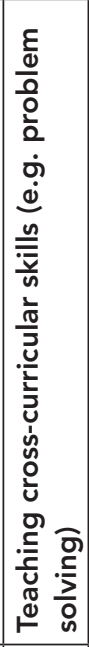 & 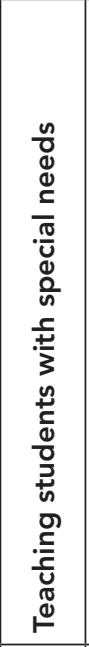 & 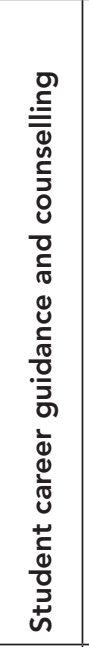 & 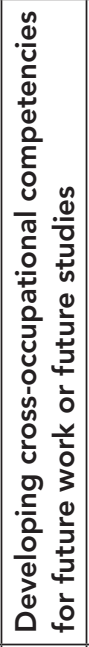 & 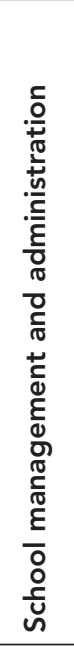 & 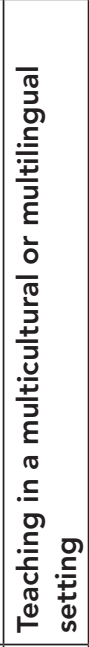 & 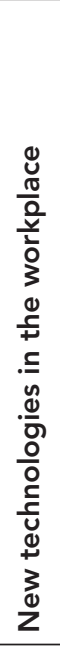 & 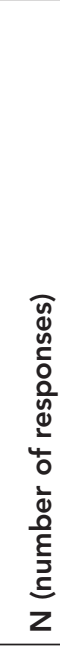 \\
\hline Aspen & 83.3 & 0 & 16.7 & 0 & 0 & 0 & 0 & 0 & 0 & 0 & 0 & 0 & 0 & 6 \\
\hline Birch & 43.5 & 28.3 & 13 & 2.2 & 0 & 0 & 0 & 0 & 2.2 & 4.3 & 4.3 & 2.2 & 0 & 46 \\
\hline Cedar & 64.7 & 0 & 11.8 & 0 & 0 & 0 & 0 & 5.9 & 5.9 & 0 & 0 & 11.8 & 0 & 17 \\
\hline $\begin{array}{l}\text { Douglas- } \\
\text { Fir }\end{array}$ & 41.7 & 16.7 & 33.3 & 0 & 0 & 0 & 4.2 & 0 & 4.2 & 0 & 0 & 0 & 0 & 24 \\
\hline Elm & 53.8 & 0 & 38.5 & 0 & 0 & 0 & 0 & 7.7 & 0 & 0 & 0 & 0 & 0 & 13 \\
\hline Fig & 42.9 & 0 & 42.9 & 0 & 0 & 0 & 0 & 7.1 & 0 & 0 & 7.1 & 0 & 0 & 14 \\
\hline Ginkgo & 57.7 & 11.5 & 3.8 & 3.8 & 3.8 & 0 & 7.7 & 3.8 & 0 & 0 & 3.8 & 3.8 & 0 & 26 \\
\hline Hawthorn & 70 & 20 & 10 & 0 & 0 & 0 & 0 & 0 & 0 & 0 & 0 & 0 & 0 & 10 \\
\hline Ivy & 50 & 0 & 37.5 & 12.5 & 0 & 0 & 0 & 0 & 0 & 0 & 0 & 0 & 0 & 8 \\
\hline Juniper & 12.5 & 25 & 12.5 & 12.5 & 0 & 0 & 12.5 & 12.5 & 12.5 & 0 & 0 & 0 & 0 & 8 \\
\hline Katsura & 90.9 & 0 & 9.1 & 0 & 0 & 0 & 0 & 0 & 0 & 0 & 0 & 0 & 0 & 11 \\
\hline Laurel & 20 & 10 & 40 & 10 & 10 & 0 & 10 & 0 & 0 & 0 & 0 & 0 & 0 & 10 \\
\hline Mahogany & 0 & 0 & 75 & 0 & 0 & 0 & 0 & 0 & 0 & 25 & 0 & 0 & 0 & 4 \\
\hline Nutmeg & 50 & 25 & 16.7 & 0 & 0 & 0 & 0 & 8.3 & 0 & 0 & 0 & 0 & 0 & 12 \\
\hline All schools & 49.8 & 13.4 & 21.1 & 2.4 & 1 & 0 & 2.4 & 2.9 & 1.9 & 1.4 & 1.9 & 1.9 & 0 & 209 \\
\hline
\end{tabular}

*The schools in the study were given tree names to protect their identities.

The second most frequently reported focus of PL perceived to be valuable was categorized as 'student evaluation and assessment practices', and this accounts for 21 per cent of all responses. The activities described were exclusively concerned with informing teachers about the new, nationally imposed curriculum and assessment agendas, a typical response being 'online exam board training in how to conduct the GCSE speaking exam'. That teachers valued a focus on revised evaluation criteria in 
order to prepare students effectively for high-stakes examinations is understandable. However, there can be little doubt that this focus has come at the expense of a variety of other potential subjects for PL (not one of the remaining OECD categories in Table 3 attracted more than 3 per cent of responses).

As expected, analysis of teachers' descriptions of the nature of their most valuable PL experiences revealed a relationship between the frequency with which teachers engaged in their most valued PL activity and the extent to which they report that their PL activity has influenced their classroom practice $(r=.35, p<0.05)$. This supports the existing literature, which suggests that one-off courses are less likely to influence teachers' practice (Cordingley et al., 2015). It is worth noting that although teachers perceived it to be valuable, the PL described in the 'student assessment' category was the most likely to take the form of one-off sessions, and was the category of PL least likely to be reported as influencing teachers' classroom practice.

\section{Factors shaping teachers' PL experiences}

A one-way ANOVA establishes that the effect of school membership on teachers' reporting of engagement in effective $P L$ activities is significant $(F(13,28)=2.1, p=.045)$ and accounts for some 50 per cent of the variance in scores $(\eta 2=.498)$. However, there remains a great deal of variability in teachers' responses within individual schools (see Table 4), which suggests that there are factors at the individual level that interact with school context in determining the extent to which teachers are able and willing to engage in the $\mathrm{PL}$ activities investigated.

Table 4: Descriptive statistics for combined scores of participation in activities characteristic of effective PL by school*

\begin{tabular}{lcccccc}
\hline School & N & $\begin{array}{c}\text { Mean } \\
\text { score }\end{array}$ & $\begin{array}{c}\text { Standard } \\
\text { deviation }\end{array}$ & $\begin{array}{c}\text { Standard } \\
\text { error }\end{array}$ & Minimum & Maximum \\
\hline Birch & 6 & 16.3 & 9.5 & 3.9 & 8 & 32 \\
Cedar & 4 & 11.8 & 11.2 & 5.6 & 0 & 27 \\
Douglas-Fir & 4 & 9 & 6 & 3 & 6 & 18 \\
Elm & 3 & 21 & 6.1 & 3.5 & 14 & 25 \\
Fig & 2 & 24 & 5.7 & 4 & 20 & 28 \\
Ginkgo & 5 & 12.2 & 6.5 & 2.9 & 5 & 20 \\
Hawthorn & 3 & 22.7 & 2.1 & 1.2 & 21 & 25 \\
Ivy & 2 & 4.5 & 6.4 & 4.5 & 0 & 9 \\
Juniper & 2 & 12 & 4.2 & 3 & 9 & 15 \\
Katsura & 3 & 20 & 1.7 & 1 & 19 & 22 \\
Laurel & 3 & 25 & 14.5 & 8.4 & 11 & 40 \\
Nutmeg & 3 & 18 & 4.6 & 2.6 & 14 & 23 \\
All schools & 40 & 16.1 & 8.8 & 1.4 & 0 & 40 \\
\hline
\end{tabular}

* Scores range from 0 (no engagement in the eight activities was reported) to 40 (strong engagement in all eight activities was reported). Schools with more than one respondent across the effective PL measures are included. Aspen and Mahogany school each had only one respondent for these items and are omitted.

An investigation into possible individual-level factors found a significant, positive correlation between teachers' sense of professional self-efficacy (as measured by the TSES developed by Tschannen-Moran and Woolfolk Hoy, 2001) and their overall 
engagement in PL activities known to be effective $(r=.43, p=.005)$. This indicates that teachers in this data set who are already confident in their classroom abilities are accessing more effective PL than their less confident counterparts. The possible underlying causes of this Matthew effect are likely to be a combination of contextual and personal factors, and warrant further investigation. While the current study cannot discern any direction of causality, TALIS data suggests that higher levels of self-efficacy may be a product of engagement in effective, school-embedded PL (Schleicher, 2016), and Hiver (2013) found that teachers with high self-efficacy were more likely to seek out 'enhancing' PL opportunities, creating a mutually reinforcing cycle.

Across the surveys, the most frequently reported barriers to PL access were lack of time, lack of funding, excessive workload and lack of cover (see Table 5). These barriers are also highlighted by all six HoDs who were interviewed. Lack of time is frequently mentioned in combination with concerns about workload, and when these two response categories are combined, they account for 59 per cent of all responses to the questions about barriers. A one-way ANOVA was run to test for school-level differences between the four most frequently reported barriers. Results indicate no significant difference by school for lack of time, funding and cover, which appear to be barriers encountered in every context. However, a statistically significant effect of school membership was found for the reporting of excessive workload $(F(8,8)=3.6$, $\mathrm{p}=.045)$. Stress levels were measured in the questionnaires via an adapted version of Fimian's Teacher Stress Inventory (1984) and, as with workload, stress levels across the academic year were found to vary significantly between schools, and school membership accounted for 54 per cent of the variance in stress scores $(F(13,30)=2.8, p=.008$, $\eta 2=0.54)$. A post hoc Tukey test showed that stress levels at Juniper school were significantly $(p<.05)$ lower than those at Mahogany and Nutmeg schools, indicating that some schools and departments have been more successful than others in resisting workplace policies and cultures that can lead to additional workload and stress.

\section{Table 5: Barriers to accessing PL mentioned across all four teacher surveys}

\begin{tabular}{lc}
\hline Barriers to accessing PL & $\begin{array}{c}\text { Frequency } \\
(\mathrm{n}=140)\end{array}$ \\
\hline Lack of time & 60 \\
Lack of funding & 27 \\
Excessive workload & 22 \\
Lack of cover & 12 \\
Timing of continuing professional development outside & 8 \\
working hours & 6 \\
Lack of opportunities & 2 \\
Lack of leadership support & 3 \\
Other & \\
\hline
\end{tabular}

Interviews with HoDs confirmed and illuminated the strains that preparation for new examinations in times of financial constraint and increasing accountability have imposed upon L2 departments. Three HoDs mentioned that an element of their role was the protection of their colleagues from excessive workload. The HoD at DouglasFir School explained that she had responded to research evidence questioning the impact of extensive marking by encouraging her team not to correct everything but to take a 'less is more approach'. However, the ability of HoDs to shield colleagues 
was limited when whole-school initiatives with workload implications were introduced: Nutmeg School HoD spoke about a school-wide programme of regular performance management observations as 'counterproductive' and as 'adding a lot of stress to peoples' lives'. He stressed the need for trust in one's colleagues, commenting that 'the vast majority are self-accountable'. Although there were no statistically significant relationships found between reported stress levels and the degree of engagement in effective $\mathrm{PL}$, stressful work environments were associated with a reduction in the extent to which teachers report planning for their professional futures. The higher their reported stress levels, the less likely teachers were to consider teaching L2 in a school setting to be a long-term career $(r=-.44, p=.004)$ and the more likely they were to see planning for their PL as a waste of time $(r=.31, p=.04)$.

All six HoDs mentioned the impact of the new examination structure on the content of PL. Elm School HoD's focus on examination board training to get 'affirmation that you're not doing a terrible job' demonstrates the way in which rapid changes in the examination structure can undermine teachers' sense of competence (Lam et al., 2010). Douglas-Fir School HoD spoke about the anxiety of her colleagues, who were becoming reliant on each other for reassurance that they were doing everything 'right', and Elm School HoD asserted that now was not the time to 'take risks'. These comments align with previous research, which has suggested that the need for conformity to deliver externally imposed educational change agendas can stifle teachers' autonomy and creativity, creating cultures of 'contrived collegiality' (Hargreaves, 1994; Jeffrey, 2002). Some HoDs countered this process by actively preserving spaces for innovation: Ginkgo School HoD spoke of the implementation of a lesson-study approach to developing new pedagogical understandings, with 'different people feeding in their opinions about "oh, why would you teach it like that?" or "what about this?"', and Katsura School HoD highlighted his fight to remain a part of a university ITE partnership, which he saw as facilitating discussion and re-evaluation of current practices in light of new research. Unfortunately, in Ivy School (also the school with the lowest average reported engagement in PL activities known to be effective), the HoD appeared to perceive new ideas brought into the department by a colleague as a threat, saying that 'it almost makes you feel a bit ... what's the word? ... as if you're not as good as they are?' An embracing of innovation and criticality from both within and beyond the department seems to be a key tool with which HoDs can work to maintain their department's sense of professional self-efficacy.

\section{Conclusions and implications}

This article set out to explore two questions:

1. To what extent are the PL experiences of teachers in the sample characteristic of 'effective' PL practices as reported in Cordingley (2015) and endorsed by the DfE (2016)?

2. What factors have shaped the PL experiences of teachers in the sample?

Across all schools, this study found low levels of engagement in PL activities known to be effective. Where teachers do report higher levels of engagement in effective $\mathrm{PL}$ practices, including $\mathrm{L} 2$-specific $\mathrm{PL}$, there is accompanying evidence of a positive association with individual teachers' sense of self-efficacy, general professional engagement and intention to remain in the profession. This study thus provides additional evidence of the need for, and potential benefits of, an increase in teachers' access to, and engagement in, effective PL in England. 
It is generally accepted that the negative wash-back effect of high-stakes examination preparation on L2 teachers' classroom practice over many years (acknowledged by Ofqual (2014)) has created a need for in-depth and sustained, subject-specific PL to help L2 teachers engage with alternative pedagogies that are informed by research into the processes of effective language learning. However, recent fast-paced curriculum and assessment change with potential to create an impetus for PL has in fact combined with time and financial constraints, as well as accountability pressures, to create a working environment that impedes teachers' engagement in effective, sustained forms of PL. The variability across school contexts in teachers' experience of excessive workload and stress (well-known barriers to PL) suggests that some department cultures are more resistant to the pressures facing all schools created by new examination systems, increasing accountability agendas and curriculum change. Given the known association between maladaptive responses to stress and teacher attrition, departments that are less successful in tackling workload and stress may face long-term negative consequences.

Analysis of the PL activities that teachers have found most valuable demonstrates a surprising level of conformity across the sample, perhaps reflecting the sharp focus on instrumental organizational aims related to the introduction of new examination specifications and curricula. Teachers report that they have valued subject-specific PL opportunities and PL that equips them to tackle the challenges of changing assessment regimes. Teachers' experiences of PL focused on the latter were found to consist almost exclusively of one-off, online examination board briefings about new GCSEs and $A$ levels. HoDs confirm that engagement in this kind of $P L$ is driven by the need to cope with, and conform to, new assessment requirements. It seems that opportunities for in-depth consideration of teaching and learning in relation to changing assessment were not readily available to the teachers in this study.

The L2 teachers' strong endorsement of opportunities to develop subject-specific knowledge and pedagogical competencies is a key finding from this study, as is the association between subject-specific PL experiences and teachers' perceptions that $P L$ has led to changes in their practice, bringing benefits for learners. These findings align with those of international studies and deliver an unambiguous message: school and faculty leaders hoping to improve student outcomes should bear in mind the accumulating evidence about the features of effective PL. Every possible attempt should be made to rationalize teacher workload and invest in protected time for teachers to engage with frequent, subject-specific development clearly linked to both teacher and student needs. A first step towards this may be to provide opportunities for subject teams to work together to contextualize generic PL for their specific situations. The framework provided by the new standard for professional development in England (DfE, 2016) is an accessible and research-informed tool to guide school leaders in building better opportunities for their staff to engage in PL activities known to be effective, enabling teachers to move beyond limited goals of 'coping' and towards deeper and richer learning with the potential to transform both classroom practice and student outcomes.

\section{Limitations}

There is some considerable scope for variety in teachers' interpretation of, and response to, the eight different activities described by Cordingley (2015). For example, the second statement contains the concepts of collaboration, risk-taking and professional dialogue. For those participants who indicated that this statement partially reflected 
their PL experience, it is not possible to discern to which specific concepts they are referring. This issue is mitigated somewhat by the inclusion of free-text responses, enabling participants to clarify their interpretations. However, these eight statements could have been better operationalized via a number of sub-statements to which participants could respond, enabling a more accurate measurement of the elements contained within them. Future research should involve the creation and testing of more reliable and valid measures of teachers' self-reported engagement in PL of different qualities.

This review of teacher PL took place one year after the introduction of significant changes in public examinations of L2 in England. A longer-term study is needed to assess whether the limited range of PL reported in this study reflects short-term consequences of these changes or whether the range of $\mathrm{PL}$ reported is stable over time.

\section{Notes on the contributor}

Laura Molway is a languages specialist and Lecturer in Initial Teacher Education at the Department of Education, University of Oxford. She also supervises practising teachers who are completing their Master's in Learning and Teaching. Her doctoral research centres on understanding the professional learning of languages teachers in secondary schools. She is also interested in L2 acquisition research, with a focus on language learning strategies and student motivation.

\section{References}

Adams, R. and Stewart, H. (2018) 'Damian Hinds pledges to help teachers overwhelmed by excessive workload'. Guardian, 20 July. Online. http://tinyurl.com/ycjmuc8c (accessed 5 April 2019).

BERA (British Educational Research Association) (2011) Ethical Guidelines for Educational Research. London: British Educational Research Association.

Burn, K., Mutton, T. and Hagger, H. (2010) 'Strengthening and sustaining professional learning in the second year of teaching'. Oxford Review of Education, 36 (6), 639-59.

Childs, A., Burn, K. and McNicholl, J. (2013) 'What influences the learning cultures of subject departments in secondary schools? A study of four subject departments in England'. Teacher Development, 17 (1), 35-54.

Coldwell, M. (2017) 'Exploring the influence of professional development on teacher careers: A path model approach'. Teaching and Teacher Education, 61, 189-98.

Cordingley, P. (2015) 'The contribution of research to teachers' professional learning and development'. Oxford Review of Education, 41 (2), 234-52.

Cordingley, P., Greany, T., Crisp, B., Seleznyov, S., Bradbury, M. and Perry, T. (2018) Developing Great Subject Teaching: Rapid evidence review of subject-specific continuing professional development in the UK. London: Wellcome Trust.

Cordingley, P., Higgins, S., Greany, T., Buckler, N., Coles-Jordan, D., Crisp, B., Saunders, L. and Coe, R. (2015) Developing Great Teaching: Lessons from the international reviews into effective professional development. London: Teacher Development Trust.

Darling-Hammond, L. (2017) 'Teacher education around the world: What can we learn from international practice?'. European Journal of Teacher Education, 40 (3), 291-309.

Darling-Hammond, L., Amrein-Beardsley, A., Haertel, E. and Rothstein, J. (2012) 'Evaluating teacher evaluation'. Phi Delta Kappan, 93 (6), 8-15.

Day, C. and Gu, Q. (2007) 'Variations in the conditions for teachers' professional learning and development: Sustaining commitment and effectiveness over a career'. Oxford Review of Education, 33 (4), 423-43.

Day, C., Stobart, G., Sammons, P., Kington, A., Gu, Q., Smees, R. and Mujtaba, T. (2006) Variations in Teachers' Work, Lives and Effectiveness (DfES Research Report RR743). Nottingham: Department for Education and Skills. Online. https://dera.ioe.ac.uk/6405/1/rr743.pdf (accessed 7 April 2019).

DfE (Department for Education) (2016) Standard for teachers' professional development. Online. https://tinyurl.com/z6jzoff (accessed 7 April 2019). 
East, M. (2015) 'Taking communication to task - again: What difference does a decade make?'. Language Learning Journal, 43 (1), 6-19.

European Commission (2012) First European Survey on Language Competences: Final report. Brussels: European Commission.

Evetts, J. (2011) 'A new professionalism? Challenges and opportunities'. Current Sociology, 59 (4), 406-22.

Fimian, M.J. (1984) 'The development of an instrument to measure occupational stress in teachers: The Teacher Stress Inventory'. Journal of Occupational Psychology, 57 (4), 277-93.

Foster, D. (2018) Teacher Recruitment and Retention in England (House of Commons Library Briefing Paper 7222). London: House of Commons Library.

Friedman, I.A. (1991) 'High- and low-burnout schools: School culture aspects of teacher burnout'. Journal of Educational Research, 84 (6), 325-33.

Friedman, I.A. (2000) 'Burnout in teachers: Shattered dreams of impeccable professional performance'. Journal of Clinical Psychology, 56 (5), 595-606.

Fullan, M. and Hargreaves, A. (eds) (1992) Teacher Development and Educational Change. London: Falmer Press.

Hargreaves, A. (1994) Changing Teachers, Changing Times: Teachers' work and culture in the postmodern age. London: Cassell.

Hargreaves, L., Cunningham, M., Everton, T., Hansen, A., Hopper, B., Mclntyre, D., Maddock, M., Mukherjee, J., Pell, T., Rouse, M., Turner, P. and Wilson, L. (2006) The Status of Teachers and the Teaching Profession: Views from inside and outside the profession: Interim findings from the Teacher Status Project (DfES Resesarch Report RR755). Nottingham: Department for Education and Skills.

Hiver, P. (2013) 'The interplay of possible language teacher selves in professional development choices'. Language Teaching Research, 17 (2), 210-27.

Hodkinson, P. and Hodkinson, H. (2004) 'The significance of individuals' dispositions in workplace learning: A case study of two teachers'. Journal of Education and Work, 17 (2), 167-82.

Hood, M. (2016) Beyond the Plateau: The case for an Institute for Advanced Teaching. London: Institute for Public Policy Research.

Ipsos MORI (2014) Why is the Take-Up of Modern Foreign Language A Levels in Decline? A report for the Joint Council for Qualifications. London: Ipsos MORI.

Jeffrey, B. (2002) 'Performativity and primary teacher relations'. Journal of Education Policy, 17 (5), 531-46.

Jensen, B., Sonnemann, J., Roberts-Hull, K. and Hunter, A. (2016) Beyond PD: Teacher professional learning in high-performing systems. Washington, DC: National Center on Education and the Economy.

Lam, S., Cheng, R.W. and Choy, H.C. (2010) 'School support and teacher motivation to implement project-based learning'. Learning and Instruction, 20 (6), 487-97.

Leonard, S.N. and Roberts, P. (2016) 'No time to think: Policy, pedagogy and professional learning'. Journal of Education Policy, 31 (2), 142-60.

Macaro, E., Graham, S. and Woore, R. (2016) Improving Foreign Language Teaching: Towards a research-based curriculum and pedagogy. London: Routledge.

NAO (National Audit Office) (2017) Retaining and Developing the Teaching Workforce. London: National Audit Office.

Ofqual (Office of Qualifications and Examinations Regulation) (2014) The Assessment of A level Modern Foreign Language: Summary of exploration of assessment quality. Coventry: Office of Qualifications and Examinations Regulation. Online. https://tinyurl.com/y2388pw3 (accessed 7 April 2019).

Opfer, V.D. and Pedder, D. (2011) 'Conceptualizing teacher professional learning'. Review of Educational Research, 81 (3), 376-407.

Sachs, J. (2016) 'Teacher professionalism: Why are we still talking about it?'. Teachers and Teaching: Theory and Practice, 22 (4), 413-25.

Schleicher, A. (2011) Building a High-Quality Teaching Profession: Lessons from around the world. Paris: OECD Publishing.

Schleicher, A. (2016) Teaching Excellence through Professional Learning and Policy Reform: Lessons from around the world: International Summit on the Teaching Profession. Paris: OECD Publishing.

Sellen, P. (2016) Teacher Workload and Professional Development in England's Secondary Schools: Insights from TALIS. London: Education Policy Institute. 
Shulman, L.S. (1986) 'Those who understand: Knowledge growth in teaching'. Educational Researcher, 15 (2), 4-14.

Sutton Trust (2011) Improving the Impact of Teachers on Pupil Achievement in the UK: Interim findings. London: Sutton Trust. Online. https://tinyurl.com/y3hp4wdj (accessed 7 April 2019).

Timperley, H. (2008) Teacher Professional Learning and Development (Educational Practices 18). Brussels: International Academy of Education.

Tinsley, T. and Board, K. (2017) Language Trends 2016/17: Language teaching in primary and secondary schools in England. London: British Council.

Tschannen-Moran, M. and Woolfolk Hoy, A. (2001) 'Teacher efficacy: Capturing an elusive construct'. Teaching and Teacher Education, 17 (7), 783-805.

Zeichner, K. (2010) 'Competition, economic rationalization, increased surveillance, and attacks on diversity: Neo-liberalism and the transformation of teacher education in the US'. Teaching and Teacher Education, 26 (8), 1544-52. 